\author{
О.М. Петровський ${ }^{1}$, С.В. Гаврилко ${ }^{2}$, Д.О. Петровська ${ }^{1}$, С.С. Сідоров ${ }^{1}$ \\ ${ }^{1}$ Полтавський національний технічний університет імені Юрія Кондратюка, Полтава \\ ${ }^{2}$ Державний університет телекомунікацій, Київ
}

\title{
МАТЕМАТИЧНЕ МОДЕЛЮВАННЯ ТА ПРОГРАМНА РЕАЛІЗАЦІЯ РОЗРАХУНКУ ТЕПЛОВИХ РЕЖИМІВ СУЧАСНИХ ПРОЦЕСОРІВ
}

\begin{abstract}
Проведено аналіз сучасних процесорів, а саме їх конструкиій та принциипів роботи. Розглянуті системи охолодження сучасної обчислювальної техніки. На основі будови процесорів та принципів їх роботи визначені режими нагрівання та теплопередачі в оточуюче середовище. Зроблене порівняння систем охолодження інтегральної мікросхеми. Запропонована фізико-математична модель процесу перерозподілу тепла в внутрішній структурі процесора на основі рівняння теплового балансу і рівняння теплопровідності Фур'є. Розроблена математична модель дозволила аналізувати температурні режими роботи процесорів 3 метою зниження температури нагрівання напівпровідникових кристалів їх внутрішньої структури, а також удосконалення процесу тепловідведення і технічних засобів систем охолодження.
\end{abstract}

Ключові слова: цеентальний прочесор, система охолодження, рівняння теплопровідності Фур'є, програмування.

\section{Вступ}

Останнім часом гонка продуктивності настільних ПК піднялася на новий рівень. Зростають тактові частоти, обчислювальні потужності, перехід на багатоядерну архітектуру і впровадження архітектури ×64 покликане підняти продуктивність ПК на новий рівень. При збільшенні тактових частот відповідно збільшується тепловиділення електронних компонентів. Так як у електронних схем працездатність забезпечується при вузькому діапазоні температур, то збільшення тепловиділення не може відбуватися нескінченно [1]. Для вирішення цієї проблеми є два шляхи: по-перше, впровадження нових процесорних архітектур, технологічних процесів, що дозволяє знизити тепловиділення, але при появі наступних процесорів відповідного сімейства ця перевага втрачається. Існує другий шлях - удосконалити системи охолодження процесорів. Саме в цьому напрямку зараз йде більшість виробників процесорів. За останні кілька років еволюція систем охолодження пройшла шлях від радіаторів, якими задовольнялися процесори Intel 80486 до сучасних систем охолодження на основі теплових нанотрубок.

Мета досліджень. Аналіз роботи процесора, його архітектури, будови та принципів роботи систем тепловідведення і примусового охолодження. Розробка фізико-математичної моделі теплових режимів роботи процесорів на основі рівняння теплопровідності Фур'є з подальшим його аналізом і програмною реалізацією.

Аналіз літературних джерел. Процесор, або більш повно мікропроцесор, (CPU - central processing unit) $\epsilon$ центральним компонентом комп'ютера. Це розум, який керує, прямо або побічно, всім, що відбувається всередині комп’ютера [2].
Сьогодні, понад півстоліття опісля створення перших процесорів, майже всі вони мають фонНейманівську архітектуру.

Основні функціональні компоненти процесора.

Ядро. Центр процесора - виконуючий модуль, який має два паралельних цілочисельних потока, що дозволяють читати, інтерпретувати, виконувати й відправляти дві інструкції одночасно. Має найбільшу частоту операцій, а відповідно екстремальний температурний режим.

Провісник розгалужень: Модуль пророкування розгалужень намагається вгадати, яка послідовність буде виконуватися щораз коли програма містить умовний перехід, так щоб пристрої попередньої вибірки й декодування одержували б інструкції готовими заздалегідь $[3,4]$.

Блок $з$ плаваючою точкою. Третій модуль, що виконує всередині нецілочисельне обчислення.

Первинний кеш. Має два внутрішньочіпових кешів по 8kb, по одному для даних і інструкцій.

Шинний інтерфейс: приймає суміш коду і даних в CPU, розділяє їх по готовності до використання, і знову з'єднує, відправляючи назовні.

Всі елементи процесора синхронізуються 3 використанням тактової частоти, яка визначає швидкість виконання операцій. Найперші процесори працювали на частоті $100 \mathrm{kHz}$, сьогодні звичайна частота процесора - $3500 \mathrm{MHz}$, інакше кажучи, вони виконують 3,5 мільярдів операцій в секунду, а кожна операція спричиняє за собою виконання багатьох дій.

Лічильник Команд (РС) - внутрішній покажчик, що містить адреси наступної виконуваної команди. Коли приходить час іiї виконання, керуючий модуль поміщає інструкцію 3 пам'яті в регістр інструкцій (IR). У той же самий час лічильник команд збільшується, так щоб вказувати на наступну інструкцію, а 
процесор виконує інструкцію в IR. Деякі інструкції управляють самим керуючим модулем, так якщо інструкція говорить перейти на адресу 2749, величина 2749 записується в лічильник команд, щоб процесор виконував цю інструкцію наступною[5]. Таким чином маємо багатомодульність і багатопроцесність обчислювальних дій, що супроводжується споживанням електричної енергії певної частоти, а відповідно до закону Джоуля-Ленца виділенням теплової енергії з наступним перерозподілом іiі в оточуюче середовище[6].

Серед найбільш важливих характеристик процесора можна перерахувати такі:

- компанія-виробник;

- тип роз'єму, до якого можна підключити такий процесор;

- швидкодія процесора;

- його модель.

Найважливішою характеристикою процесора $є$ швидкодія, яка з точки зору як продуктивності так i теплових режимів роботи - основна. Перш за все, слід визначитися 3 поняттям такту. Отже, одна математична або логічна операція виконується процесором за 1 такт, таким чином, кількість тактів в одиницю часу визначає кількість виконуваних процесором операцій. Відомо, що частота в $1 \mathrm{~Hz}$ відповідає 1 коливанню в секунду. У комп'ютерних технологіях 1 електричне коливання відповідає одному такту процесора. Таким чином, при частоті електричних коливань в $1 \mathrm{~Hz}$ процесор виконував би 1 математичну або логічну операцію в секунду. Частота електричних коливань, що задає швидкість роботи CPU, називається тактовою частотою процесора. При тактовій частоті в $1 \mathrm{MHz}$ процесор вже здатний виконувати мільйон операцій за секунду, при частоті в $100 \mathrm{MHz}-100$ млн операцій. Проводячи нескладну аналогію, можна сказати, що тактова частота подібна оборотами двигуна автомобіля (чим вони вищі, тим більшу потужність розвиває мотор), або метроному, який підказує музикантові швидкість програвання мелодії. Тактова частота сучасних процесорів може досягати 1, 2 або навіть $5 \mathrm{GHz}$, тобто подібні процесори здатні виконувати кілька мільярдів операцій в секунду. Чим вище тактова частота, тим вище продуктивність і швидкодія процесора. 3 іншого боку частоти вище $1 \mathrm{GHz}$ це так званий надвисокочастотний (НВЧ) діапазон електромагнітних коливань якому властиве інтенсивне виділення тепла тілами, що задіяні в таких процесах. По суті процесор працює в режимі мікрохвильової печі (частота коливань СВЧ-печі складає $2840 \mathrm{MHz}$ ).

Кількість теплоти, що виділяється в комп'ютері залежить не тільки від тактової частоти процесора, хоча ця характеристика $є$ основною і вирішальною під час проектування системи охолодження, але і від загального вмісту системного блоку, від його енер- госпоживання. Це зовсім не означає, що охолоджувати потрібно абсолютно всі задіяні складові системного блоку. Але сучасні центральні процесори i процесори відео адапторів без охолодження ніяк не можуть обійтися, інакше неминуче їх руйнування в наслідок нагріву[7-10].

Від тепловиділення, на жаль, нікуди не дітися, але ж ця проблема має чимало рішень. Інше питання яким чином доцільно охолоджувати в конкретному випадку для певного процесора. На даний момент існує досить багато систем охолодження, всі вони використовують загальний принцип дії - перенесення тепла від більш гарячого тіла (охолоджуваного об'єкта) до менш гарячого (системи охолодження). Розглянемо наступні системи:

Кулер це сукупність радіатора і вентилятора, що встановлюється на електронні компоненти комп'ютера $з$ підвищеною тепловіддачею.

Система рідинного охолодження - це така система охолодження, в якості теплоносія в якій виступає рідина з високою теплоємністю. Вода в чистому вигляді рідко використовується в якості теплоносія (пов'язано це 3 електропровідністю і корозійною активністю води), частіше це дистильована вода (з різними добавками антикорозійного характеру), іноді - масло, інші спеціальні рідини.

Серед нестандартних систем охолодження можна відзначити одну дуже ефективну систему - на основі елементів Пельтьє.

Не дуже поширений, але дуже ефективний клас систем охолодження - системи з холодоагентом в яких використовують фреони.

Також є системи, в якості холодоагенту в яких використовується рідкий азот. Рідкий азот являє собою прозору рідину, без кольору і запаху, температурою кипіння (при нормальному атмосферному тиску) якої дорівнює -195,8 градусів за Цельсієм. Для зберігання рідкого азоту застосовують спеціальні резервуари - судини Дьюара об'смом від 6 до 40 літрів. Установки даного типу призначені тільки для екстремального охолодження, в екстремальних умовах. Одним словом, при розгоні тобто надмірному збільшенні тактової частоти.

На сьогоднішній день не існує проблеми охолодження, як такої, а існує проблема відбирання i перенесення тепла від поверхні процесора в навколишнє середовище. До систем охолодження пред'являються високі і часом взаємовиключні вимоги: вони повинні бути ефективними, безшумними, недорогими[3-5].

Таким чином $є$ доцільним створення фізикоматематичної моделі теплових режимів процесорів яка $\epsilon$ необхідною при проектуванні процесорів i систем охолодження комп'ютерів. Модель може бути реалізована за допомогою мови програмування C++ в середовищі Microsoft Visual Studio [1]. 


\section{Основні результати досліджень}

Процесор під час роботи нагрівається нерівномірно, крім того він контактує з навколишнім середовищем і віддає частину теплоти. Таким чином, спостерігається явище нерівномірності розподілу температур, а відповідно - процес теплопровідності.

У загальному випадку температура $\mathrm{T}$ у різних точках тіла змінюється з часом і за просторовими координатами. Цей процес може бути представлений загальною формулою [6]:

$$
\mathrm{T}=\mathrm{f}(\mathrm{x}, \mathrm{y}, \mathrm{z}, \mathrm{t}),
$$

де $\mathrm{x}, \mathrm{y}, \mathrm{z}$ - координати точки; $\mathrm{t}$ - час.

Вигляд функції $\mathrm{f}$ визначається за допомогою диференційного рівняння теплопровідності Фур'є, яке в загальному випадку має вигляд

$$
\frac{\partial \mathrm{T}_{(\mathrm{x}, \mathrm{y}, \mathrm{z}, \mathrm{t})}}{\partial \mathrm{t}}=\alpha \nabla^{2} \mathrm{~T}_{(\mathrm{x}, \mathrm{y}, \mathrm{z}, \mathrm{t})}+\mathrm{q},
$$

де $\mathrm{T}(\mathrm{x}, \mathrm{y}, \mathrm{z}, \mathrm{t})$ - температура в точці координатами $\mathrm{x}$, $\mathrm{y}, \mathrm{z}$ в час $\mathrm{t}, \mathrm{K} ; \alpha$ - коефіцієнт температуропровіднос$\mathrm{ri}, \mathrm{m}^{2} / \mathrm{c} ; \mathrm{V}^{2}$ - диференційний оператор Лапласа; q кількість теплоти, що виділяється в одиниці об'єму за одиницю часу, Вт/см ${ }^{3}$.

У процесі роботи інтегральна мікросхема знаходиться у спеціальній ніші, яка називається сокетом закриваючий бокові стінки по периметру, тому теплопередачею через бокові поверхні можна знехтувати. В такому випадку функція розподілу температур у процесорі буде залежати тільки від однієї координати і має вигляд[11]:

$$
\frac{\partial \mathrm{T}_{(\mathrm{x}, \mathrm{t})}}{\partial \mathrm{t}}=\alpha \frac{\partial^{2} \mathrm{~T}_{(\mathrm{x}, \mathrm{t})}}{\partial \mathrm{x}^{2}}+\mathrm{q} .
$$

Нехай загальна площа процесора, що знаходиться під радіатором, має товщину 21. Координати торцевих країв поверхні інтегральної мікросхеми, відповідно, $\mathrm{x}_{1}=-1$ і х $\mathrm{x}_{2}=+1$.

Умови теплообміну на краях процесора повинні відповідати крайовим умовам Ньютона:

$$
\begin{aligned}
& \left.\lambda \frac{\partial \mathrm{T}}{\partial \mathrm{x}}\right|_{\mathrm{x}=-1}=\mathrm{h}\left(\left.\mathrm{T}\right|_{\mathrm{x}=-1}-\mathrm{T}_{0}\right), \\
& -\left.\lambda \frac{\partial \mathrm{T}}{\partial \mathrm{x}}\right|_{\mathrm{x}=+1}=\mathrm{h}\left(\left.\mathrm{T}\right|_{\mathrm{x}=+1}-\mathrm{T}_{0}\right),
\end{aligned}
$$

де: $\lambda$ - ефективний коефіцієнт теплопровідності процесора, Дж/см К; $\mathrm{h}$ - коефіцієнт теплообміну на краях процесора, $\mathrm{BT} /\left(\mathrm{cm}^{2} \cdot \mathrm{K}\right) ; \mathrm{T}_{0}$ - температура зовнішнього середовища, К.

Для розв'язку задачі теплопровідності далі зручно вести відлік температур від температури навколишнього середовища. У цьому випадку крайові умови мають вигляд $[6,11]$ :

$$
\left.\lambda \frac{\partial \mathrm{T}}{\partial \mathrm{x}}\right|_{\mathrm{x}=-1}=\left.\mathrm{hT}\right|_{\mathrm{x}=-1},
$$

$$
-\left.\lambda \frac{\partial \mathrm{T}}{\partial \mathrm{x}}\right|_{\mathrm{x}=+1}=\left.\mathrm{hT}\right|_{\mathrm{x}=+1}
$$

де $\mathrm{T}-$ перевищення температури над температурою навколишнього середовища, К.

Розв'язок задачі має остаточний вигляд

$$
\mathrm{T}(\mathrm{x}, \mathrm{t})=\frac{2 \mathrm{Ptl}}{\lambda \mathrm{S}}\left[\begin{array}{c}
\frac{1}{4}\left(1-\frac{\mathrm{x}^{2}}{1^{2}}\right)+\frac{\lambda}{2 \mathrm{lh}}-\cos \left(\gamma_{\mathrm{n}} \frac{\mathrm{x}}{1}\right) \times \\
\times \sum_{\mathrm{n}=1}^{\infty} \frac{\mathrm{e}^{-\gamma_{\mathrm{n}}^{2} \cdot \tau / 1^{2}} \sin \gamma_{\mathrm{n}}}{\left(1+\sin \left(2 \gamma_{\mathrm{n}}\right) /\left(2 \gamma_{\mathrm{n}}\right)\right)}
\end{array}\right],
$$

де $\gamma_{\mathrm{n}}$ - позитивні корені рівняння; $\mathrm{P}$ - потужність, що виділяється в процесорі, Вт; $\mathrm{S}$ - площа поверхні процесора за координатою $\mathrm{x}, \mathrm{m}^{2}$;

$$
\begin{gathered}
\operatorname{tg} \gamma=\operatorname{lh} / \gamma\left(\gamma_{1}<\gamma_{2}<\ldots\right) ; \\
\tau=\frac{\lambda \mathrm{t}}{\mathrm{c} \rho},
\end{gathered}
$$

де с - питома теплоємність, Дж/(кг · К); $\rho$ - густина середовища, кг/м3.

Аналіз рішення (7) показує, що воно задовольняе початковій умові $\left.\mathrm{T}\right|_{\mathrm{t}=0}=0$. Для радіатора центрального процесора, коли $\mathrm{x}=0$, вираз (7) приймає вигляд

$$
\mathrm{T}(0, \mathrm{t})=\frac{2 \mathrm{Ptl}^{2}}{\lambda \mathrm{lS}}\left[\frac{1}{4}+\frac{1}{2 \mathrm{lh}}-\sum_{\mathrm{n}=1}^{\infty} \frac{\mathrm{e}^{-\gamma_{\mathrm{n}}^{2} \frac{\tau}{1^{2}}} \sin \gamma_{\mathrm{n}}\left(1+\frac{\sin 2 \gamma_{\mathrm{n}}}{2 \gamma_{\mathrm{n}}}\right)}{\gamma^{3}}\right]
$$

Практичне застосування вказаного методу має певні незручності, оскільки потребуе вирішення трансцендентного рівняння, а також визначення необхідної кількості членів суми, що треба отримати в рівнянні, для забезпечення необхідної точності результатів.

У такому випадку для чисельних розрахунків використовується метод кінцевих різниць. Сутність методу полягає в заміні неперервних величин дискретними значеннями

(4) $x_{j}, j=0,1,2, \ldots, n, \quad t_{i}, i=0,1,2, \ldots, m$.

Введення дискретних значень приводить до наступних наближених формул відповідних похідних.

$$
\begin{gathered}
\frac{\partial \mathrm{T}}{\partial \mathrm{t}}=\frac{\mathrm{T}_{\mathrm{i}=1, \mathrm{j}}-\mathrm{T}_{1, j}}{\Delta \mathrm{t}}, \\
\frac{\partial^{2} \mathrm{~T}}{\partial \mathrm{x}^{2}}=\frac{\left(\mathrm{T}_{\mathrm{i}, \mathrm{j}+1}-\mathrm{T}_{\mathrm{i}, \mathrm{j}}\right) / \Delta \mathrm{x}-\left(\mathrm{T}_{\mathrm{i}, \mathrm{j}}-\mathrm{T}_{\mathrm{i}, \mathrm{j}-1}\right) / \Delta \mathrm{x}}{\Delta \mathrm{x}}= \\
=\left(\mathrm{T}_{\mathrm{i}, \mathrm{j}+1}-2 \mathrm{~T}_{\mathrm{i}, \mathrm{j}}+\mathrm{T}_{\mathrm{i}, \mathrm{j}-1}\right) / \Delta \mathrm{x}^{2} .
\end{gathered}
$$

Внаслідок цього розв'язок рівняння (3) можемо одержати за рахунок обчислення наступного рівняння: 
$T_{i+1, j}=T_{i, j}+\left(\alpha\left(\frac{T_{i, j+1}-2 T_{i, j}+T_{i, j-1}}{\Delta x^{2}}\right)+q\right) \Delta t .(11)$

3 урахуванням крайових умов:

$$
\frac{\mathrm{T}_{1}}{\Delta \mathrm{x}}=\mathrm{h}^{\prime} \mathrm{T}_{1}, \quad \frac{\mathrm{T}_{\mathrm{n}}}{\Delta \mathrm{x}}=-\mathrm{h}^{\prime} \mathrm{T}_{\mathrm{n}} .
$$

Стійкість рішення задачі здійснюється тільки за умови

$$
\Delta \mathrm{t}<\frac{\Delta \mathrm{x}^{2}}{2 \alpha} .
$$

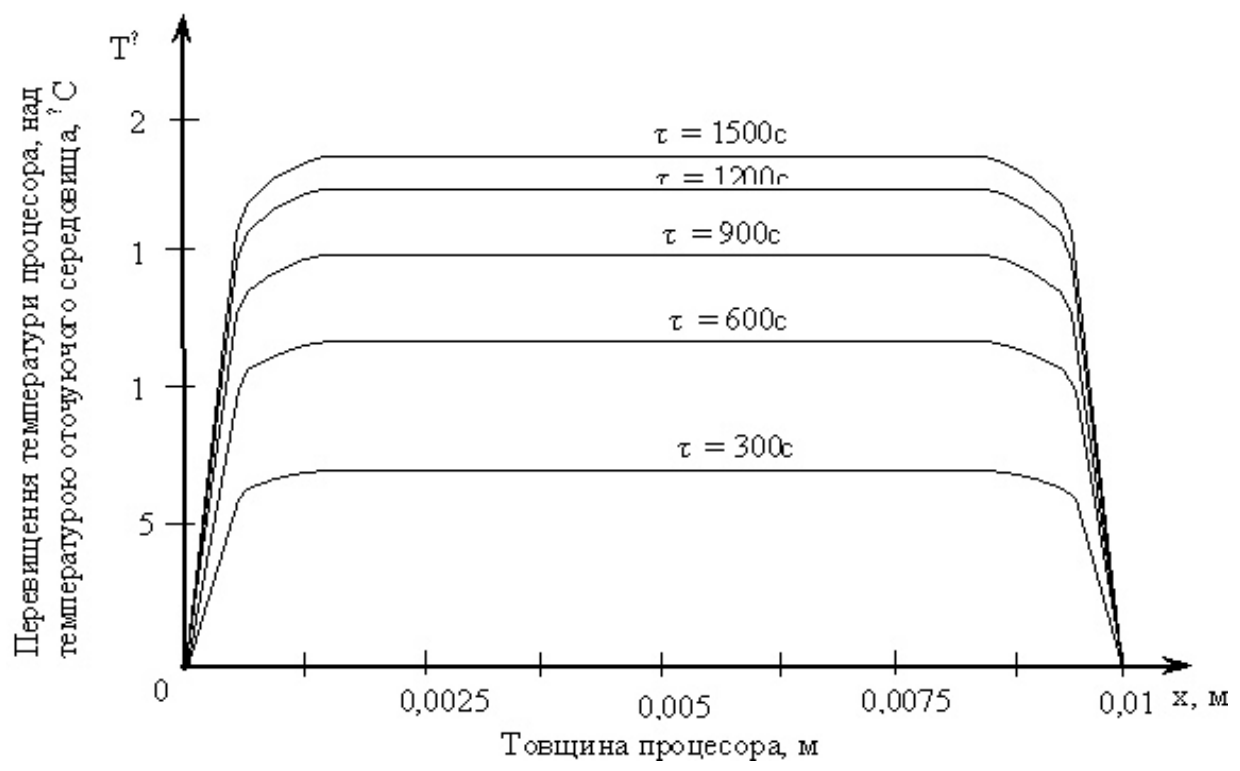

Рис. 1. Розподіл температур в процесорі за різного часу роботи

Згідно 3 аналізом моделі температурного режиму, за достатньої тривалості роботи $(\mathrm{t} \rightarrow \infty)$ температура процесора $\mathrm{T}$ досягає свого максимального
Для проведення чисельних розрахунків необхідно попередньо визначити ряд параметрів: середню питому теплоємність, коефіцієнт теплообміну Ньютона, коефіцієнт теплопровідності.

Числові значення розподілу температур у процесорі можуть бути обраховані за допомогою розглянутої моделі методом кінцевих різниць, використовуючи розроблену комп'ютерну програму (рис. 1).

Максимального значення температура досягає в середньому шарі кристалів процесора, причому максимальна температура прямо пропорційна потужності і частоті.

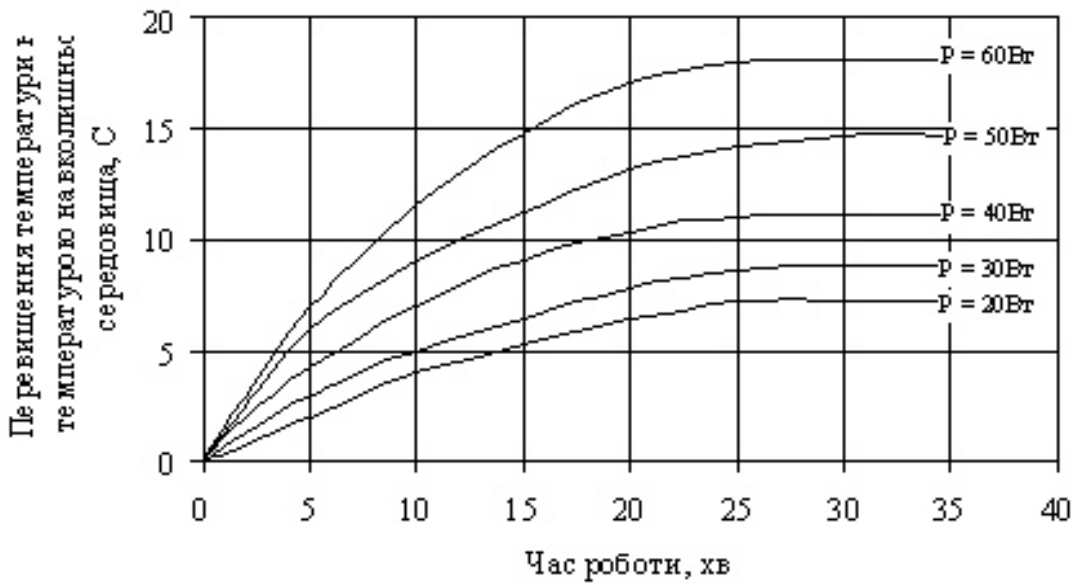

Рис. 2. Температура процесора за різних потужностей

Вони достатньо добре можуть бути апроксимовані рівнянням

$$
\mathrm{T}=\mathrm{T}_{\infty}\left(1-\mathrm{e}^{-\mathrm{t} / \mathrm{t}_{0}}\right),
$$

значення і далі практично не змінюється. Цей висновок ілюструється результатами, представленими на рис. 2. 
Температура $\mathrm{T}_{\infty}$ відповідає усталеному режиму, в тому випадку, коли одержане тепло і його втрати рівні.

\section{Висновки}

Проведений аналіз центральних процесорів та їх систем охолодження засвідчив необхідність інтерпретації і теоретичного дослідження фізичних процесів теплових режимів їх роботи з подальшою реалізацією математичної моделі.

Розроблена фізико-математична модель розрахунку теплових режимів роботи процесорів на основі рівняння теплового балансу і рівняння теплопровідності Фур'є, яка враховує будову, конструктивні особливості розміщення, умови застосування та принципи тепловідведення.

Запропонована фізико-математична модель дозволяє визначити теплові режими процесорів за різної тривалості роботи і при різній потужності навантаження.

Проведені чисельні розрахунки зміни температури процесора за тривалості роботи від 300 до 1500 c, а також при зміні потужності навантаження 20, 30, 40, 50, 60 Вт.

Теоретично доведено, що при будь-якій величині навантаження температура процесора змінюється за експоненціальним законом і він виходить на усталений режим роботи за 25 - 30 хв.

Зменшення температури всередині процесора можливе лише за рахунок більш інтенсивного тепловідведення, що можливо реалізувати застосовуючи матеріали з високим коефіцієнтом температуропровідності і використовуючи системи активного охолодження.

\section{Список літератури}

1. Компания MySQL AB. MySQL. Руководство администратора. - М.: Издательский дом «Вильямс», 2005. $-624 c$.

2. Бруно Бабэ. Просто и ясно о Borland $C++$ : Пер. $с$ англ. - Москва: БИНОМ, 1994. 400с.

3. Скляров В.А.. Язык $C++$ и объектноориентированное програмлирование: Справочное издание. - Минск: Вышиэйшая школа, 1997. 480с.

4. Мураховський В. I. Залізо ПК. Нові можливості. СПб.: Питер, 2005. 324c.

5. Світ ПК серпня 2005 мікропрочесори сьогодні $і$ завтра. Лоусон Б., Шари Р. Изучаем HTML5. Библиотека специалиста. - СПб.: Питер, 2011. - 272 c.

6. Яворский Б. М. Справочник по физике : [для инженеров и студентов вузов] / Б. М. Яворский, А. А. Детлаф : [издание четвёртое, переработанное]. - М. : Нау$\kappa a, 1968 .-939 c$

7. Вамберский М. В. Передающие устройства СВЧ : [учеб. пособие для радиотехнич. спеи. вузов] / М. В. Вамберский В. И. Казанщев: [под ред. М. В. Вамберского]. М. : Высшая шкшкола, 1984. - 448 c.

8. Гусев В. Г. Электроника / В. Г. Гусев, Ю. М. Гусев. - М. : Высшая школа, 1991. - 622 c.

9. Горбачев Г. Н. Промышленная электроника : [учебник для вузов] / Г. Н. Горбачев, Е. Е. Чапльгин. - М. : Энергоатомиздат, 1988. - 320 c.

10. Грабовски Б. Справочник по электронике / Богдан Грабовски : [пер. с фр. А. В. Хаванов. - 2-е изд., uсnр.]. - М. : ДМК Пресс, 2009. - 416 c.

11. Уваренков И.М. Курс математического анализа [в 2 m.] : [учебное пос. для физико-математических факультетов педагогических институтов] / И.М. Уваренков, М.3. Малер. - Т. 2. - М. : Просвещение, 1976. - 479 с.

Надійшла до редколегї̈ 11.12.2017

Рецензент: д-р. техн. наук, проф. Л. І. Лєві, Полтавський національний технічний університет імені Юрія Кондратюка, Полтава.

\section{МАТЕМАТИЧЕСКОЕ МОДЕЛИРОВАНИЕ И ПРОГРАММНАЯ РЕАЛИЗАЦИЯ РАСЧЕТА ТЕПЛОВЫХ РЕЖИМОВ СОВРЕМЕННЫХ ПРОЦЕССОРОВ}

А.Н. Петровский, Е.В. Гаврилко, Д.А. Петровская, С.Е. Сидоров

Проведен анализ современных процессоров, а именно их конструкиий и принципов работы. Рассмотрены системы охлаждения современной вычислительной техники. На основе строения проиессоров и принципов их работы определены режимы нагрева и теплопередачи в окружаюмую среду. Проведено сравнение систем охлаждения интегральной микросхемы. Предложенная физико-математическая модель проиесса перераспределения тепла в внутренней структуре процессора на основе уравнения теплового баланса и уравнения теплопроводности Фурье. Разработанная математическая модель позволила анализировать температурные режимы работы процессоров с иелью снижения температуры нагрева полупроводниковых кристаллов их внутренней структуры, а также совершенствования проиесса теплоотвода и технических средств систем охлаждения. рование.

Ключевые слова: иеентральный процессор, система охлаждения, уравнение теплопроводности Фурье, программи-

\section{MATHEMATICAL MODELING AND SOFTWARE REALIZATION OF CALCULATION OF THERMAL MODES OF MODERN PROCESSORS}

O.M. Petrovskiy, E.V. Gavrilko, D.O. Petrovska, S.E. Sidorov

The analysis of modern processors, namely their designs and operating principles, is carried out. The cooling systems of modern computer technology are considered. On the basis of the structure of the processors and the principles of their operation, the modes of heating and heat transfer into the environment are determined. The cooling systems of an integrated microcircuit are compared. The proposed physicomathematical model of the process of heat redistribution in the internal structure of the processor is based on the heat balance equation and the Fourier heat equation. The developed mathematical model allowed analyzing the temperature modes of operation of processors in order to reduce the temperature of heating of semiconductor crystals of their internal structure, as well as to improve the heat removal process and the technical means of cooling systems.

Keywords: central processor, cooling system, Fourier heat equation, programming. 